\title{
Airborne transmission during short-term events under stratum ventilation
}

\author{
Kaho Hashimoto ${ }^{1,2}$, Zhengtao $\mathrm{Ai}^{1}$, and Arsen Melikov ${ }^{1}$ \\ ${ }^{1}$ International Center for Indoor Environment and Energy, Department of Civil Engineering, Technical University of Denmark, 2800 \\ Kongens Lyngby, Denmark \\ ${ }^{2}$ Department of Architecture, Waseda University, 168-8555 Shinjuku-ku Okubo, Japan
}

\begin{abstract}
Past studies on airborne spread of expiratory droplet nuclei between occupants were focused on long-term exposure under steady-state conditions. However, exposure during short-term events can be widely found in practice, e.g. medical examination or short meeting. Airborne transmission during shortterm events under stratum ventilation was examined experimentally in this study. Two breathing thermal manikins were employed to simulate a standing infected person and a standing exposed person. The manikins were placed face-to-face and face-to-back to reproduce the exposure conditions with the highest and the lowest risk, respectively. Tracer gas was dosed into the air exhaled by the "infected" manikin to simulate the droplet nuclei. A newly developed average exposure index was used to evaluate the exposure risk. The time-averaged exposure index increases over time, but the increasing rate depends strongly on the duration of exposure time, e.g., the exposure index increases much faster during the first 5 minutes than during the period after 5 minutes. The exposure index during short-term events does not always decrease with the increase of separation distance. These findings imply that the control measures formulated based on steady-state conditions are not necessarily effective to short-term events.
\end{abstract}

\section{Introduction}

Infectious diseases such as influenza impair the health of infected people and also cause medical expense burdens, increased absenteeism and decreased productivity, which result in economic losses [1][2]. In addition, health relates to the quality of life [3]. Preventing the spread of airborne infection is therefore an important issue worldwide.

Past studies have shown that under well air mixing and steady-state room conditions the risk of airborne infection sharply decreases with the increase of distance between infected person and exposed person [4]. However, there is still a need to consider the risk of airborne infection in case of short-term events, e.g., 10 min medical examination. In this case, it takes time to reach the steady state and the dynamic interaction of breathing flows involving human plume evolves. In addition, the survival rate of some viruses decreases over time. It is therefore important to investigate the dynamic exposure risk over time immediately after the droplet nuclei is being released.

The purpose of the present study was to investigate airborne transmission between infected person and exposed person during short-term events.

\section{Method}

\footnotetext{
* Corresponding author :hashimoto@tanabe.arch.waseda.ac.jp
}

\subsection{Experimental conditions}

Experiments were conducted in a climate chamber at the Technical University of Denmark. The volume of the chamber was $4.4 \mathrm{~m} \times 4.7 \mathrm{~m} \times 2.6 \mathrm{~m}$. The room air temperature was controlled to be $24 \pm 0.5{ }^{\circ} \mathrm{C}$ but the relative humidity was not controlled while it was measured to be approximately from $30 \%$ to $40 \%$ during experiments. Two breathing thermal manikins were adopted to simulate infected person and exposed person. The body surface temperature of the manikins and the generated heat were controlled by a computer program to be as those of an average person in state of comfort. Manikins were equipped with artificial lungs. The simulated breathing cycle was $2.5 \mathrm{~s}$ for inhalation, $2.5 \mathrm{~s}$ for exhalation, and $1.0 \mathrm{~s}$ for break. The respiratory volume was $6.0 \mathrm{~L} / \mathrm{min}$, and the breathing frequency was 10 times per minutes. In this experiment, the" infected" manikin inhaled from nose and exhaled from mouth that is similar to the normal talking condition; the exposed manikin inhaled from mouth and exhaled from nose.

Figure 1 shows the two manikins in the climate chamber ventilated by stratum ventilation. The manikins were positioned face-to-face and face-to-back, in order to represent the greatest and the lowest risk of exposure respectively [5] [6]. The distances between the two manikins were set as $0.5 \mathrm{~m}, 1.0 \mathrm{~m}$, and $1.5 \mathrm{~m}$. Figure 2 
shows picture photo of the experimental set up where the manikins placed as face-to-face and face-to-back arrangements. Table 1 shows a list of the experimental conditions. The stratum ventilation is known as an effective system to prevent high exposure because the supplied air enters the breathing zone directly [7]. The air is supplied to the room from wall located terminal devices. In this experiment the temperature of supply air flow was $16{ }^{\circ} \mathrm{C}$. The height of the air supply and exhaust terminals were $1.9 \mathrm{~m}$ above the floor. Four supply and four exhaust terminals with diameters of $0.16 \mathrm{~m}$ positioned at distance $0.44 \mathrm{~m}$ between each other were used. The airflow was supplied from the back of exposed manikin when the positioning was face-to-face, and from the front of the infected manikin when the positioning was face-to-back.

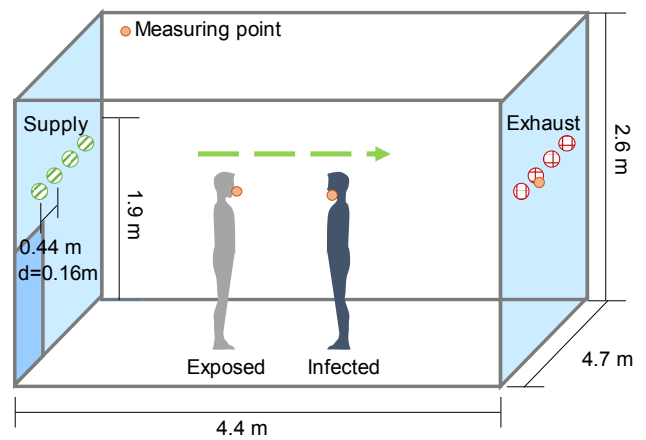

(a) Face-to-Face

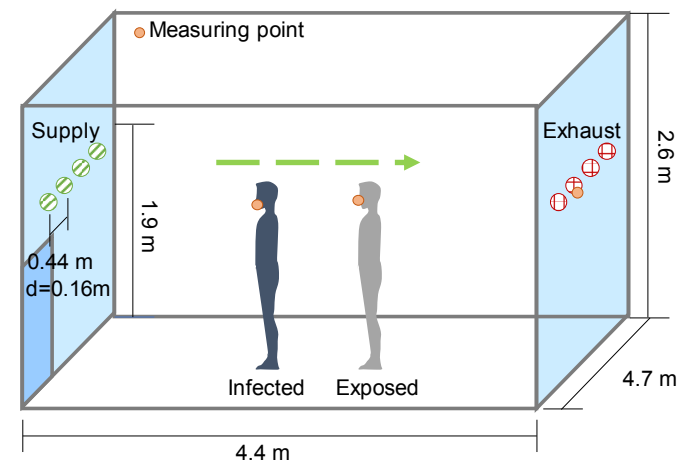

(b) Face-to-Back

Fig. 1. Positioning of two manikins under the stratum ventilation

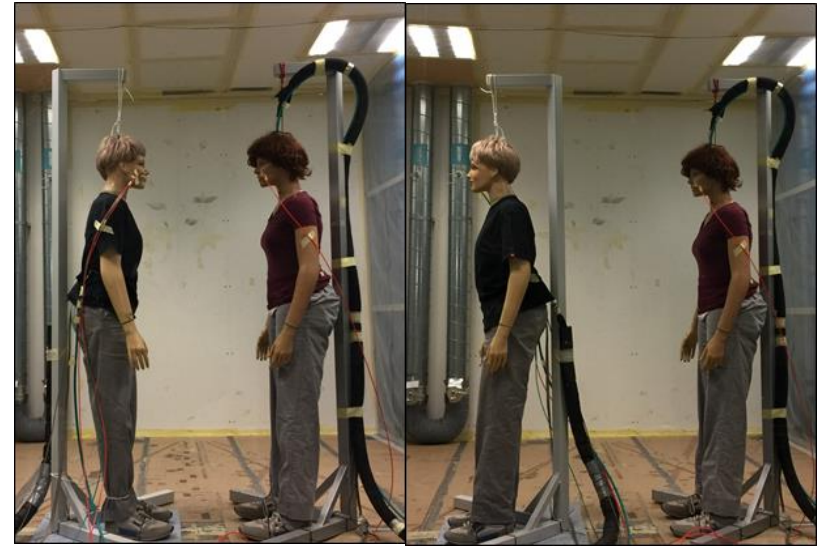

Fig. 2. Views of experimental set up, the manikins are placed face-to-face and face-to-back
Table 1. The experimental conditions

\begin{tabular}{|c|c|c|c|c|}
\hline & $\begin{array}{c}\text { Supply } \\
\text { flow rate } \\
(1 / \mathrm{s})\end{array}$ & ACH $\left(\mathrm{h}^{-1}\right)$ & $\begin{array}{c}\text { Positioning } \\
\text { of manikin }\end{array}$ & $\begin{array}{c}\text { Separation } \\
\text { Distance (m) }\end{array}$ \\
\hline 1 & 30 & 2 & Face-to-face & \\
\cline { 1 - 4 } 2 & 30 & 2 & $\begin{array}{c}\text { Face-to- } \\
\text { back }\end{array}$ & \multirow{2}{*}{$0.5,1.0,1.5$} \\
\cline { 1 - 4 } 3 & 90 & 6 & Face-to-face & \\
\cline { 1 - 3 } 4 & 90 & 6 & $\begin{array}{c}\text { Face-to- } \\
\text { back }\end{array}$ & \\
\hline
\end{tabular}

\subsection{Measuring method}

\subsubsection{Tracer Gas}

Tracer Gas $\mathrm{N}_{2} \mathrm{O}$ was used to simulate the droplet nuclei exhaled from the infected manikin. The tracer gas concentration was measured at the mouth of the infected manikin, the mouth of the exposed manikin, and the exhaust air terminal. The tracer gas was dosed after steady-state flow conditions were reached in the chamber.

\subsubsection{Fast Concentration Meter}

Most past studies used the INNOVA instrument to measure the concentration of tracer gas. However, the response time of INNOVA is $40 \mathrm{~s}$ per one channel (for the model 1312). Since the breathing cycle is $6 \mathrm{~s}$ in total, the INNOVA cannot track the tracer gas concentration changes during short-term events. Therefore, a Fast Concentration Meter (FCM) was adopted in this experiment. The resolution of the FCM was $1.0 \mathrm{ppm}$ and the expanded uncertainty was $\pm 20.0 \mathrm{ppm} \quad(95 \%$ confidence level). The sampling rate of the instrument was $4 \mathrm{~Hz}$ i.e. 4 sampling per second and made it possible to catch the dynamics of the transmission.

\subsection{New Exposure Index}

So far two indexes have been used to evaluate exposure: the Intake Fraction $(I F)$ [8] and the Exposure Index $\left(\varepsilon_{s}\right)$ [9-20].

The Intake Fraction index was defined as the proportion of inhalation of exposed person to exhalation of infected person.

$$
I F(t)=\frac{\int_{0}^{t_{i n}} C_{\text {in }}(t) M_{\text {in }} d t}{\int_{0}^{t_{e x}} C_{e x}(t) M_{e x} d t}
$$

$C_{i n}$ is the inhaled concentration of exposed person, $C_{e x}$ is the exhaled concentration of the infected person, $M_{i n}$ and $M_{e x}$ are mass flow rates of inhaled flow of the exposed person and that of exhaled flow of the infected person at time $t$, respectively, $t_{i n}$ and $t_{e x}$ are the inhalation time of 
the exposed person and the exhalation time of the infected person, respectively.

The Intake Fraction index cannot be used for evaluation of short events because first, the exhaled $\mathrm{N}_{2} \mathrm{O}$ concentration in the flow exhaled by the infected person is sensitive to where the measuring point. The Exposure Index $\left(\varepsilon_{s}\right)$ was defined as the ratio of the inhaled tracer gas concentration by exposed person to the concentration at exhaust terminal. This index was more widely used than the Intake fraction index.

$$
\overline{\varepsilon_{s}(t)}=\frac{\overline{\left[C_{\text {in }}(t)-C_{\text {supply }}(t)\right]}}{\left[C_{\text {exhaust }}(t)-C_{\text {supply }}(t)\right]}
$$

$C_{\text {supply }}$ is the concentration at supply terminal, $C_{\text {exhaust }}$ is the concentration at exhaust terminal, and the bar means the average concentration during the duration time of $t$. In this case, since supplied air is induced from outside the trace gas concentration in the supply air is 0 . $C_{\text {exhaust }}$ is 0 at the beginning of the experiment because it takes time for the $\mathrm{N}_{2} \mathrm{O}$ to reach the exhaust terminal after being released by the exhalation of the infected person. Therefore, extremely high exposure index can be obtained at the beginning of an event, which is therefore not reliable to be used for the evaluation of short-term events but only available after reached steady state.

To evaluate the short-term events, new Exposure Index was developed in this study (Eqs. 3 and 4).

$$
\begin{aligned}
& \varepsilon_{d}(t)=\frac{C_{\text {in }}(t)}{\overline{C_{\text {exhaust-steady }}}} \\
& \overline{\varepsilon_{d}(t)}=\frac{\overline{C_{\text {in }}(t)}}{\overline{C_{\text {exhaust-steady }}}}
\end{aligned}
$$

where $\varepsilon_{d}(t)$ and $\overline{\varepsilon_{d}(t)}$ indicate the real-time exposure index and the average exposure index, respectively, $C_{\text {exhaust-steady }}$ is the average concentration at the ventilation exhaust under steady-state conditions. It should be noted that the average concentration at exhaust terminal during steady-state conditions is always used regardless of the duration time of an event. However, it should be noted that the New Exposure Index can be used under the assumption that the dosing rate of tracer gas is stable during the whole process of experiments.

\section{Result}

\subsection{Real-time and Average Exposure Index}

Figure 3 shows the result of the real-time exposure index under the condition of face-to-face, when the distances are $0.50 \mathrm{~m}, 1.0 \mathrm{~m}$, and $1.5 \mathrm{~m}$ with the air change rate of $2 \mathrm{~h}^{-1}$. The figure indicates that the fluctuations were large at the shortest distance. The standard deviations of the fluctuations were $0.80,0.20$, and 0.22 for the distance of $0.5 \mathrm{~m}, 1.0 \mathrm{~m}$, and $1.5 \mathrm{~m}$, respectively. Figure 4 shows the accumulated moving average exposure index for the same conditions as in Figure 3. Compared with the realtime exposure index, the average exposure index has low fluctuations. The results in Figure 4 show that the exposure level increases rapidly during the first 3 minutes and slowly after 5 minutes when the distance is
$0.5 \mathrm{~m}$. Therefore, the average exposure index was adopted to analyse the data.

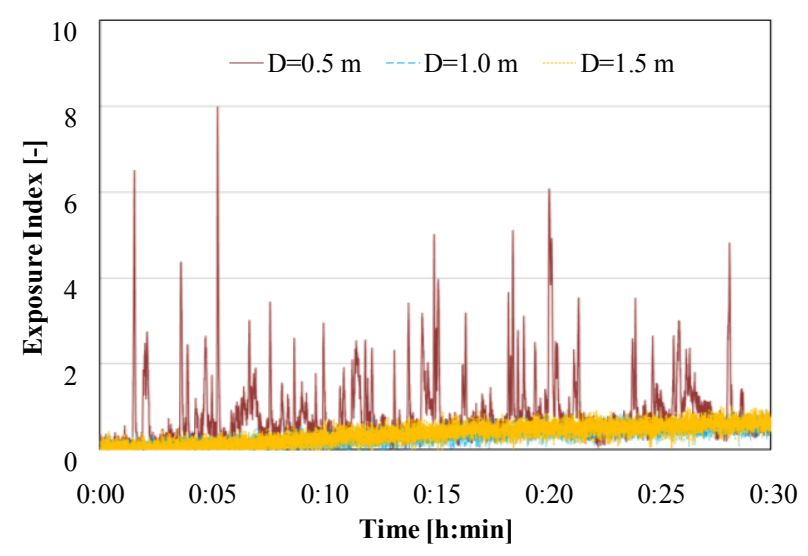

Fig. 3. The real-time exposure level under the condition of $2 \mathrm{ACH}$, positioning of face-to-face

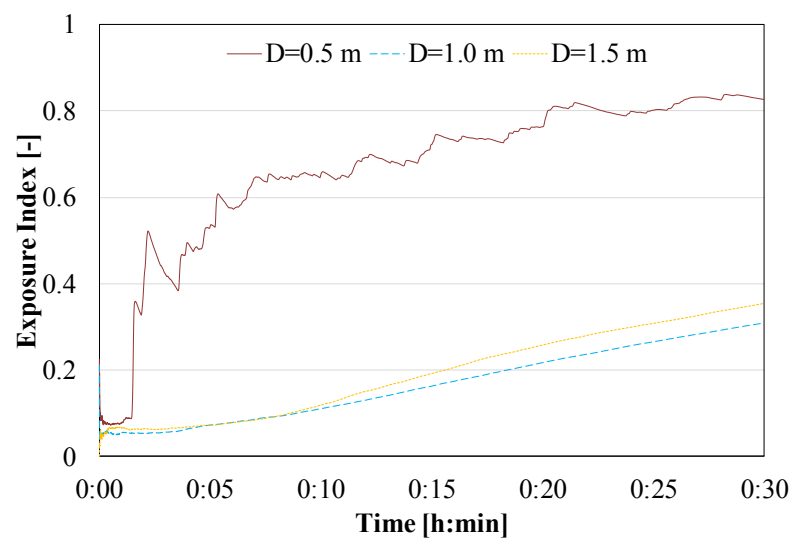

Fig. 4. The moving average exposure level under the condition of $2 \mathrm{ACH}$, positioning of face-to-face

\subsection{The Influence of Positioning}

Figures 5 and 6 compare the change of average exposure index in time for face-to-face positioning of the manikins at distance of $0.5,1.0$ and $1.5 \mathrm{~m}$. Results at air change rate of $2 \mathrm{~h}^{-1}$ and $6 \mathrm{~h}^{-1}$ are presented in the figures. The longer time of the exposure, the higher the exposure level was. When the air change rate was $2 \mathrm{~h}^{-1}$, the distance of $1.0 \mathrm{~m}$ between the two manikins was enough to reduce considerably the exposure level. However, when the air change rate was $6 \mathrm{~h}^{-1}$, the average exposure indexes at $1.0 \mathrm{~m}$ and $1.5 \mathrm{~m}$ became higher than those at the $2 \mathrm{~h}^{-1}$

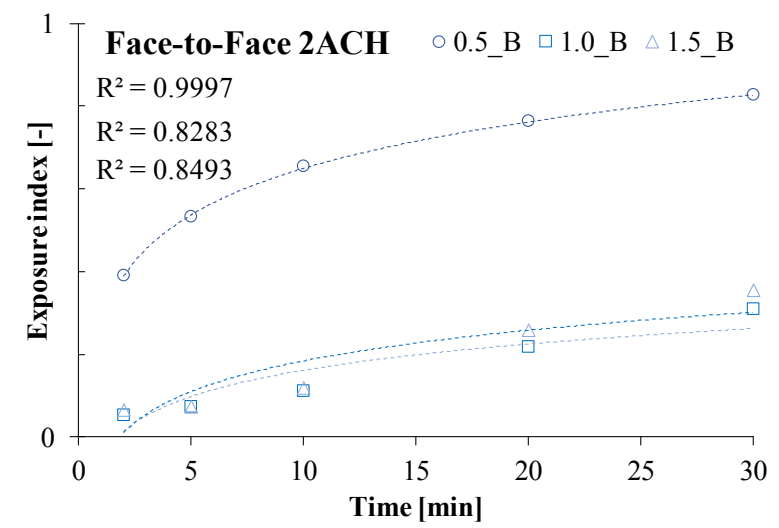




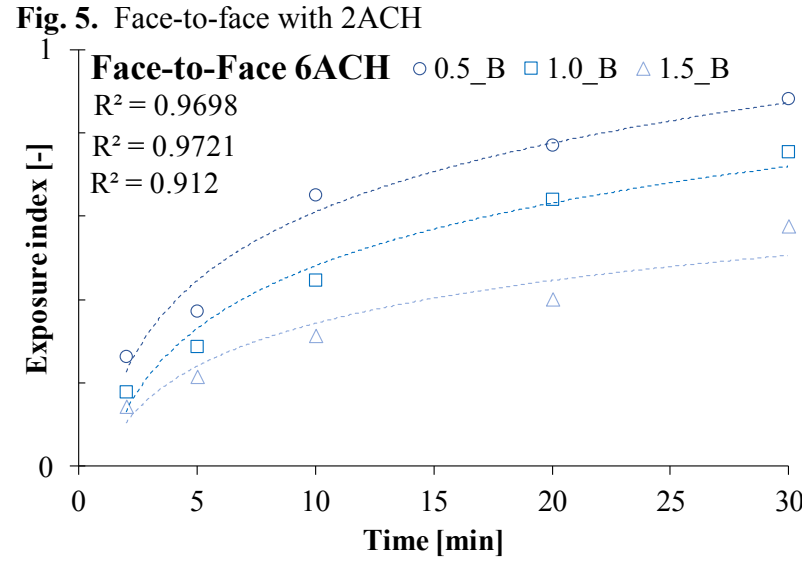

Fig. 6. Face-to-face with $6 \mathrm{ACH}$

Figures 7 and 8 show comparison of the average exposure index at different distances between the manikins positioned face-to-back at air change rate of 2 $\mathrm{h}^{-1}$ and $6 \mathrm{~h}^{-1}$ during short-term events. The comparison of the results in the figures show that the average exposure index at the three distances are similar to each other. The gradient of the change of the average exposure index is smaller at $2 \mathrm{ACH}$ than at $6 \mathrm{ACH}$. In addition, the exposure index during short-term events does not always decrease with the increase of separation distance.

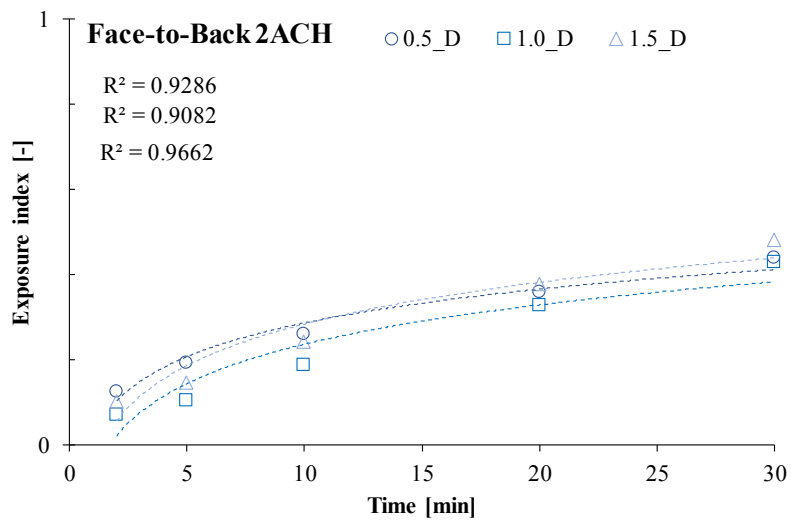

Fig. 7. Face-to-back with $2 \mathrm{ACH}$

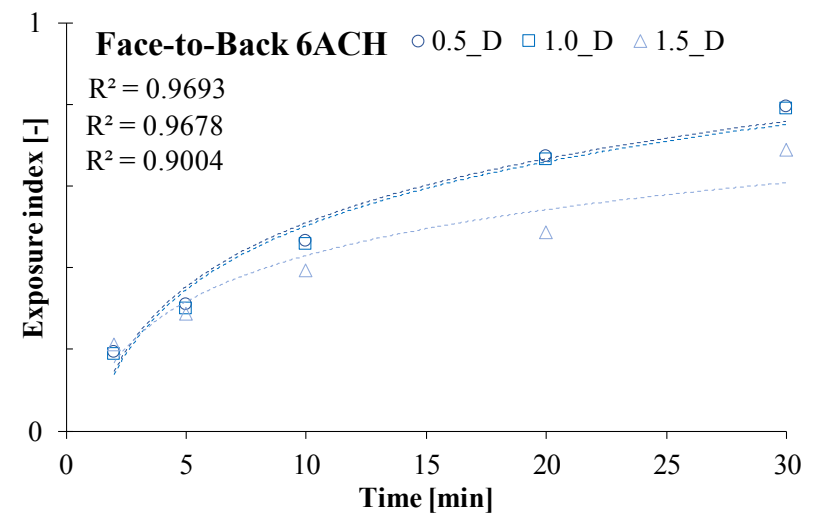

Fig. 8. Face-to-back with $6 \mathrm{ACH}$

\section{Discussion}

New Exposure index enabled the evaluation of exposure level during short-term events by using the steady-state average concentration at exhaust terminal, while past indexes have limitations for evaluation of short-term events. Though the real-time exposure index has a high fluctuation, the average exposure index indicated the change over time clearly. Therefore, the new exposure index is useful to evaluate the exposure during shortterm event under the assumption that tracer gas is released constantly.

The results revealed that in the case of face-to-face positioning, the distance between two persons should be longer than $1.0 \mathrm{~m}$ in order to have a relatively low exposure risk.

The distance shorter than $0.5 \mathrm{~m}$ should be avoided because the exposure index is very high regardless of the amount of air change rate.

\section{Conclusion}

New exposure index induced as the ratio of the cumulated-inhaled-concentration to the cumulatedaverage-exhaust-concentration was established. The index is useful to evaluate the exposure level under the short-term events. The index was applied to study exposure risk under stratum ventilation.

It was found that high exposure cannot be avoided when the distance between two persons is less than 0.5 $\mathrm{m}$.

The average exposure index increases over time, but the increasing rate depends on the duration of the exposure time.

The average exposure index during short-term events does not always decrease with the increase of separation distance.

The findings of this study are different from those obtained based on steady-state conditions, implying that the control measures formulated based on steady-state conditions are not necessarily effective to short-term events.

The present study shows the influence of positioning of two manikins and air change rate under the condition of stratum ventilation. The direction of air flow is different in other air distribution modes, e.g. mixing ventilation and displacement ventilation, and its impact on exposure needs to be studied.

\section{Acknowledgement}

The research leading to these results has received funding from the People Programme (Marie Curie Actions) of the European Union's Seventh Framework Programme (FP7/2007-2013) under REA grant agreement no. 609405 (COFUNDPostdocDTU). Dr. Zhengtao Ai, is a recipient of the Marie Curie Fellowship. Kaho Hashimoto participated in this research as a guest visiting student at The Technical University of Denmark. Her stay was funded by Japan Public-Private Partnership Student Study Abroad Program. Prof. Melikov is leading the research on ventilation and room air distribution at the International Center for Indoor Environment and Energy, Department of Civil Engineering, Technical University of Denmark. 


\section{References}

1. B. Thomas J, L. Debra, S. Matthew, Journal of Occupational and Environmental Medicine, 44(2002)

2. R. Kelly A, B. Paloma, K. R. Plotkin, L. Y. Sifuentes, D. W. Koenig, C. P. Gerba, Archives of Environmental \& Occupational Health, 71(2014)

3. N. C. Elder, S. Will, P. Harini, S. Kbaja, M. Blacker, Journal of the American Board of Family Medicine, 27(2014)

4. Z. Ai, A. K. Melikov, Indoor Air, 28(2018)

5. J. Pantelic, K. W. Tham, D. Licina, Indoor Air, 25(2015)

6. J. Yang, C Sekhar, K.W.D. Cheng, B. Raphael, Science and Technology for the Built Environment, 21(2015)

7. Z. Lin, T. Yao, T.T. Chow, L. S. Chan, Fuel and Energy Abstracts, 46(2011)

8. W. W. Nazaroff, Indoor Air 14(2004)

9. J. M. Villafruela, I. Olmedo, J. F. San Jose, Building and Environment 112(2016)

10. H. Qian, Y. Li, Indoor Air, 20(2010)

11. J. Pantelic, K. W. Tham, HVAC\&R Research, 19(2013)

12. Z. D. Bolashikov, M. Barova, A. K. Melikov, W. Kierat, HVAC\&R Research, 18(2012)

13. C. Yang, X. Yang, B. Zhao, Building Simulation, 9(2016)

14. S. W. Zhu, S. Kato, J. H. Yang, Building and Environment 41(2006)

15. P. V. Nielsen, I. Olmedo, M. Ruiz de Adana, HVAC\&R Research, 18(2012)

16. A. K. Melikov, V. Dzhartov, K. Kostadinov, International Conference on Healthy Buildings, 2012

17. L. Liu, Y. Li, P. V. Nielsen, Indoor Air, 27(2016)

18. N. P. Gao, J. L. Niu, Atomospheric Environment, 41(2007)

19. G. Cao, S. Liu, B. E. Boor, A. Novoselac, Aerosol and Air Quality Research, 15(2015)

20. G. N. Sze To, M. P. Wan, C. Y. H. Chao, L. Fang, A. K. Melikov, Aerosol Science and Technology, 43(2009) 